\title{
Atopy and Asthma in Migrants: The Function of Parasites
}

\author{
Menachem Rottem ${ }^{a, b} \quad$ Carmi Geller-Bernstein ${ }^{c}$ Yehuda Shoenfeld ${ }^{c, d}$ \\ a Division of Allergy, Asthma and Immunology, Emek Medical Center, Afula, ${ }^{\mathrm{b}}$ Rappaport Faculty of Medicine, \\ Technion - Israel Institute of Technology, Haifa, 'Zabludowicz Center for Autoimmune Diseases, Sheba Medical \\ Center, Tel Hashomer, and ${ }^{\mathrm{d}}$ Sackler Faculty of Medicine, Tel Aviv University, Tel Aviv, Israel
}

\section{Key Words}

Allergy $\cdot$ Helminths $\cdot$ Immunology $\cdot$ Infectious diseases

\begin{abstract}
Migration studies have shown that environmental factors in more developed and industrialized countries facilitate atopy and asthma in a time-dependent manner and are affected by age at immigration. Levels of immunoglobulin $E$ are higher in immigrants than in the local population and gradually decrease to the levels of the general population. Parasitic infestation may function in the prevention and pathogenesis of atopic conditions in immigrants from developing countries. Helminths are associated with a reduced prevalence of clinically important atopic disorders, likely because of induction of a regulatory cell population mechanism. Improved understanding of the immunologic background of helminths and their protective function in humans has led to a growing interest in the possibility of reversal of allergies using parasites and the development of new therapies, such as immunomodulation for allergy using ova from parasites orally or intranasally. Strategies for primary prevention in high-risk atopic individuals and secondary prevention guidelines should be developed for populations in developing countries and for immigrants from developing countries to atopy-prevalent developed countries. Improved under-
\end{abstract}

standing of the function of parasitic infection in modulation of the immune response may lead to new therapeutic options for allergic conditions.

(c) 2015 S. Karger AG, Basel

\section{Introduction}

The prevalence of atopy and asthma varies markedly throughout the world, being higher in affluent and developed countries than in less affluent and developing countries [1]. Atopy and asthma result from the effects of environmental factors on genetically susceptible people. Therefore, climate changes and migration may have an important effect on the development of allergic diseases and asthma [2]. Although climate changes are slow, migration causes an immediately different exposure to a new composition of environment and allergens. Migration studies provide information about the function of environmental factors in the development of atopy and asthma. Studying the effects of migration on the incidence of atopy and asthma in immigrants may help identify the reasons for the different prevalences of these conditions around the world and explain the effects of genetic background and infection. 


\section{Clinical Studies}

The prevalence of atopy and allergy in immigrants has been studied in different countries around the world, and similar patterns have been described. Allergy and asthma usually develop several years after migration to developed countries, and symptoms increase with time [3-10]. These progressive changes in allergic and asthma symptoms suggest that either prolonged environmental exposure or other additional risk factors are required for the development of atopy and asthma in immigrants. One of the largest studies performed about trends in the prevalence of atopic disorders is the European Community Respiratory Health Survey [11]. The frequencies of asthma symptoms were higher in immigrants and emigrants than in nonimmigrants after controlling for region, sex, age, and smoking status. However, bronchial responsiveness and atopy were equally distributed between immigrants, emigrants, and nonmigrants.

Several studies conducted in Israel on immigrants from Ethiopia and the former Soviet Union (FSU) revealed a more distinct presentation in migrants compared to native-born Israelis [12-17]. The Israeli experience was based on 2 major distinct populations of immigrants from Ethiopia and the FSU. This enabled investigators to evaluate large but very distinct populations of immigrants who moved from one to a totally different specific environment. Infections and parasitic diseases were the dominant health problems in the early years after immigration. With time, a change in health patterns in the Ethiopian population was observed, especially a marked increase in allergic diseases and asthma compared to the frequencies reported at the time of migration to Israel [12]. The move from the dry climate and rural hills of Ethiopia to the more urban and industrialized setting of Israel probably contributed to the increased prevalence of asthma in this population.

A total of 30,000 Ethiopian Jewish immigrants arrived in 2 distinct waves in 1984 and 1991. Most Ethiopian immigrants had parasitic infections and very high immunoglobulin E (IgE) levels but no symptoms of allergy or asthma [13]. Upon reassessment within 1 and 3 years after their arrival, they mostly were cured of parasitic infections and their IgE levels were significantly lower. However, 3 years after their arrival, $11 \%$ had acquired and presented with allergic manifestations, mainly allergic rhinitis and asthma due to house dust mites. The total average IgE levels in Israeli newborns of Ethiopian descent were similar to those of newborns of Israeli descent. In addition, the total IgE in Ethiopian newborns was affected only by the IgE of the mother and not that of the father. Follow-up of Ethiopian immigrant children who lived in Israel for $\geq 7$ years showed total IgE levels similar to those of age-matched healthy native Israeli children. However, in asthmatic children the total average IgE levels were higher in children of Ethiopian immigrants compared to children of non-Ethiopian Israelis [15]. A further investigation published in 2013 showed that the prevalence of asthma was $7.5 \%$ in children of Ethiopian origin, compared to $10.0 \%$ in the control group of age-matched Israeli-born children who were not of Ethiopian descent [16]. Another Israeli study showed that in Ethiopian immigrants who lived in Israel for 8-17 years there was an unusually high prevalence of asthma [17]. These studies performed in Israel are unique compared to other studies conducted worldwide because the entire population of Ethiopian immigrants was treated for parasitic infestation immediately after arrival and had a major environmental change from a rural environment to an industrialized urban and almost parasite-free environment. Of note, the Israeli population as in other countries gets treated for parasites only as needed, based on stool analyses and clinical symptoms.

During the same 30 years, 1,000,000 immigrants arrived in Israel from the FSU and gradually adapted to the lifestyle in Israel. Their health problems included tuberculosis [18] and radiation effects in immigrants coming from the Chernobyl region [19]. A 10-year prospective study of FSU-born children compared to Israeli-born children initially showed similar sensitizations to house dust mites but differences in sensitizations to pollens which matched the previous exposures of these children in the FSU and Israel [14]. The allergy skin tests were performed within a few weeks after their arrival, most likely reflecting the sensitizations they arrived with. With time, the immigrant children acquired sensitizations to the Israeli pollens and gradually lost their previous pollen sensitizations. These changes were noticed mostly from age 5-8 years.

More recent studies of immigrants to Italy confirmed that environmental factors functioned in the induction of upper and lower respiratory allergies more so than genetic factors that were a further promoting factor [2022]. Migrant children had a lower prevalence of asthma symptoms than children born in Italy. The prevalence of asthma symptoms increased with increases in the number of years living in Italy, suggesting that exposure to environmental factors may contribute to the development of asthma in childhood. The prevalence of respiratory symptoms was lower in migrant children than in DOI: $10.1159 / 000431360$
Rottem/Geller-Bernstein/Shoenfeld 
children born in Italy, and the prevalence increased with the number of years living in Italy [21]. However, a more recent study did not show significant differences in respiratory allergic diseases in immigrant children born either in Italy or abroad compared to children born to Italian parents [23]. A study in Sweden showed that age at immigration was a more important determinant of purchased inhaled steroids for asthma than population of origin, and it revealed the importance of environmental factors for asthma in schoolchildren and young adults $[10,24]$. Early-life exposure is particularly important as a risk factor for the development of allergies and asthma [25-27]. The latter studies confirmed the previous observations including our experience in Israel.

In general, IgE levels of immigrants from less developed to more developed countries decline and reach levels approximately similar to those of the local population after 10 years. The allergic spectrum of sensitization changes with time to that of residence after migration $[6$, $7,10,12,28-31]$. This change in reactivity to environmental allergens is probably related to changes in lifestyle and habits, such as indoor contact with house dust mites, pets, and intensive environmental pollen exposure, and suggests that environmental factors rather than hereditary differences determine the IgE status. However, studies in immigrants showed that there is also a genetic and particularly maternal pattern of inheritance of $\operatorname{IgE}[13$, 32]. These studies showed that the immunologic status of immigrants is affected by the new milieu, and within a few years the allergic status of immigrants adapts and/or reacts to the new environment. Living in less developed countries or a rural environment may confer protection from atopic disorders, as suggested by the hygiene hypothesis $[33,34]$. However, moving to industrialized centers in developed countries adds a new and completely different environmental exposure from which immigrants seem not to be protected. Continuous exposure to new allergens, pollutants, changes in diet, and changes in housing conditions lead to the gradual emergence of atopic disorders. The protection conferred by the past rural environment does not apply to the new environment, making immigrants more susceptible to atopic disorders.

\section{Atopy and Parasitic Infections}

The effect of infections in preventing atopy and asthma has gained much support in recent years with the hygiene hypothesis. The hygiene hypothesis, based on epidemiologic studies, hypothesizes the presence of an in- verse relation between infections during childhood and the development of atopic disorders that is accompanied by a shift from the nascent Th2 response to a Th1 response [33-38]. T-regulatory cells may function in the reduction of antigen-responsive Th2 cells [39]. Recent clinical and epidemiologic studies have shown that the increasing prevalence of allergic disorders such as asthma, allergic rhinitis, food allergy, eczema, and allergic conjunctivitis has an inverse relation to parasitic infections [40-44]. Studies have also shown a direct relation between the individual parasitic burden, blunting of the allergen response, and an increase in allergies with antiparasitic treatment. In several helminthic diseases, $\operatorname{IgE}$ is involved in protection of the host against the parasitic agent, consistent with the hypothesis that parasitic infection competes for the IgE-Th2 lymphocyte-eosinophil response [45]. This does not contradict the indication and need to treat helminthic infections in populations or individuals suffering from such infections regardless of their allergic status.

The immunologic mechanisms responsible for $\operatorname{IgE}$ production that are protective in helminthic infections are similar to those for the production of specific $\operatorname{IgE}$ against allergens. Helminthic colonization prevents the subsequent development of allergen-induced eosinophilic airway inflammation and allergen-specific Th2 cytokine production despite promoting overall increases in the general Th2 inflammatory milieu. Helminths may decrease the risk of allergies by stimulating the production of high levels of polyclonal IgE that are capable of blocking $\mathrm{FC}$ receptors on mast cells, or by promoting high levels of regulatory cytokines capable of downregulating the allergic response [46].

We investigated the apparent inverse relation of the Th2 pathway between atopic disorders and parasitic infections by examining the common conserved domains (amino acid sequences) that exist in both allergens and parasites [47]. Our results support the concept that common domains may exist between species that stimulate the Th2 pathway response - parasites and common allergens. We identified strongly homologous protein sequences from known allergens and compared them against sequences from tropical and more temperate parasites that may competitively drive the antigenic domain for IgE binding. We demonstrated that conserved domains exist in specific parasites and allergens, thus supporting the theory that the human IgE-mediated immune response to common allergens could be a direct consequence of the parasitic burden. This may explain how the human IgE response to the selected helminthic enzymes 
is responsible for allergy to many common aeroallergens. Our data showing homologies between parasites and allergens support the observations and studies of the protective effect of parasitic infections on the development of atopy and asthma. Atopic individuals may be reacting to allergens as if they were parasites, launching a destructive, misdirected immune response. Although amino acid sequence homology does not predict antigen cross-reactivity with IgE antibodies, additional studies may help to better explain the immune response relation between aeroallergens and parasitic antigens. Experimental infection of mice with gastrointestinal nematodes led to the inhibition of mucosa-associated allergic reactions [48]. When human peripheral blood mononuclear cells from allergic patients were treated with filarial cystatin, the in vitro immune response was modulated toward a Th1 profile [49]. Thus, helminthic colonization appears to provide protection or diminution of the allergic and asthmatic response, suggesting a potential function of shared antigens between parasites and environmental allergens in modulating the immune response. Early antiparasitic treatment studies noted that IgE levels and eosinophil counts decreased; when atopic disorders such as asthma were treated with the same infectious agents (hookworms and whipworms), the IgE response was apparently redirected $[50,51]$. A recent randomized double-blind study with Trichris suis showed no therapeutic effect on grasspollen-induced disease [52], but the conclusions were disputed by others $[53,54]$.

\section{Conclusion}

In summary, migration and exposure to different environmental factors have an important effect on the development of atopy and asthma, and the prevalence of atopy and asthma in migrants increases with time. Migration to allergy-prevalent countries is associated with a higher prevalence of allergies and asthma in immigrants compared with the prevalence of atopy in their countries of origin. The increase in allergy and asthma prevalence usually is not related to ethnicity, but genetic factors may be important in selected populations. Studies on immigrants support the hypothesis that lifestyle and environmental factors facilitate atopy and asthma in Western industrialized countries. The effect is time dependent, and the development of allergy is affected by the age at immigration. Compared to the local population, recent immigrants have higher levels of IgE, which gradually decrease to the levels of the general population, and a higher prevalence of atopy and allergies. Immigrants and their physicians should be aware of the potential risk of developing allergies and/or asthma. Strategies for primary prevention in high-risk atopic individuals and secondary prevention guidelines should be developed for populations in developing countries and immigrants from developing countries to atopy-prevalent developed countries.

Helminth infections are associated with a reduced prevalence of clinically important atopic disorders, and this is likely the result of induction of a regulatory cell population mechanism. Improved understanding of the immunologic background of helminths and their protective role in humans has led to a growing interest in the possibility of reversal of allergies using parasites and the development of new therapies, such as immunomodulation for allergy using ova from parasites orally or intranasally. A better understanding of the effects of parasitic infection in modulation of the immune response may lead to new therapeutic options for allergic conditions. Treatment of allergy with helminthic gene products still needs to be thoroughly studied in animals and humans before any recommendations for clinical practice can be made. Such an approach will need to be compared to current treatments for allergic conditions and especially immunotherapy.

\section{References}

1 Rottem M, Szyper-Kravitz M, Shoenfeld Y: Atopy and asthma in migrants. Int Arch Allergy Immunol 2005;136:198-204.

2 D’Amato G, Rottem M, Dahl R, Blaiss M, Ridolo E, Cecchi L, Rosario N, Motala C, Ansotegui I, Annesi-Maesano I; WAO Special Committee on Climate Change and Allergy: Climate change, migration, and allergic respiratory diseases: an update for the allergist. World Allergy Organ J 2011;4:120-125.
3 Peat JK, Woolcock AJ, Leeder SR, Blackburn CR: Asthma and bronchitis in Sydney schoolchildren. 2. The effect of social factors and smoking on prevalence. Am J Epidemiol 1980;111:728-735.

4 Gibson PG, Henry RL, Shah S, Powell H, Wang H: Migration to a Western country increases asthma symptoms but not eosinophilic airway inflammation. Pediatr Pulmonol 2003;36:209-215. 
5 Powell CV, Nolan TM, Carlin JB, Bennett CM, Johnson PD: Respiratory symptoms and duration of residence in immigrant teenagers living in Melbourne, Australia. Arch Dis Child 1999;81:159-162.

6 Leung RC, Carlin JB, Burdon JG, Czarny D: Asthma, allergy and atopy in Asian immigrants in Melbourne. Med J Aust 1994;161: 418-425.

7 Leung R: Asthma, allergy and atopy in Southeast Asian immigrants in Australia. Aust N Z J Med 1994;24:255-257.

8 Leung R: Asthma and migration. Respirology 1996;1:123-126.

9 Tedeschi A, Barcella M, Bo GA, Miadonna A: Onset of allergy and asthma symptoms in extra-European immigrants to Milan, Italy: possible role of environmental factors. Clin Exp Allergy 2003;33:449-454.

10 Grüber C, Illi S, Plieth A, Sommerfeld C, Wahn U: Cultural adaptation is associated with atopy and wheezing among children of Turkish origin living in Germany. Clin Exp Allergy 2002;32:526-531.

11 Tobias A, Soriano JB, Chinn S, Anto JM, Sunyer J, Burney P; European Community Respiratory Health Survey: Symptoms of asthma, bronchial responsiveness and atopy in immigrants and emigrants in Europe - European Community Respiratory Health Survey. Eur Respir J 2001;18:459-465.

12 Rosenberg R, Vinker S, Zakut H, Kizner F, Nakar S, Kitai E: An unusually high prevalence of asthma in Ethiopian immigrants to Israel. Fam Med 1999;31:276-279.

13 Geller-Bernstein C: Genetic and environmental determinants in the pathogenesis of allergic diseases. Pediatr Pulmonol Suppl 1997;16: 13-14.

14 Geller-Bernstein C, Kenett R: Allergies in immigrants. Eur Ann Allergy Clin Immunol 2004;36:313-316.

15 Iancovici Kidon M, Stein M, Geller-Bernstein C, Weisman Z, Steinberg S, Greenberg Z, Handzel ZT, Bentwich Z: Serum immunoglobulin E levels in Israeli-Ethiopian children: environment and genetics. Isr Med Assoc J 2005;7:799-802.

16 Shani M, Band Y, Kidon MI, Segel MJ, Rosenberg R, Nakar S, Vinker S: The second generation and asthma: prevalence of asthma among Israeli born children of Ethiopian origin. Respir Med 2013;107:519-523.

17 Pereg D, Tirosh A, Lishner M, Goldberg A, Shochat T, Confino-Cohen R: Prevalence of asthma in a large group of Israeli adolescents: influence of country of birth and age at migration. Allergy 2008;63:1040-1045.

18 Chemtob D, Weiler-Ravell D, Leventhal A, Bibi H: Epidemiologic characteristics of pediatric active tuberculosis among immigrants from high to low tuberculosis-endemic countries: the Israeli experience. Isr Med Assoc J 2006;8:21-26.
19 Kordysh EA, Goldsmith JR, Quastel MR, Poljak S, Merkin L, Cohen R, Gorodischer R: Health effects in a casual sample of immigrants to Israel from areas contaminated by the Chernobyl explosion. Environ Health Perspect 1995;103:936-941.

20 Burastero SE, Masciulli A, Villa AM: Early onset of allergic rhinitis and asthma in recent extra-European immigrants to Milan, Italy: the perspective of a non-governmental organisation. Allergol Immunopathol (Madr) 2011; 39:232-239.

21 Lombardi C, Penagos M, Senna G, Canonica GW, Passalacqua G: The clinical characteristics of respiratory allergy in immigrants in Northern Italy. Int Arch Allergy Immunol 2008; 147:231-234.

22 Lombardi C, Fiocchi A, Raffetti E, Donato F, Canonica GW, Passalacqua G; P-IGRAM Study Group: Cross-sectional comparison of the characteristics of respiratory allergy in immigrants and Italian children. Pediatr Allergy Immunol 2014;25:473-480.

23 Migliore E, Pearce N, Bugiani M, Galletti G, Biggeri A, Bisanti L, Caranci N, Dell'Orco V, De Sario M, Sestini P, Piffer S, Viegi G, Forastiere F, Galassi C, Ciccone G; SIDRIA-2 Collaborative Group: Prevalence of respiratory symptoms in migrant children to Italy: the results of SIDRIA-2 study. Allergy 2007;62: 293-300.

24 Bråbäck L, Vogt H, Hjern A: Migration and asthma medication in international adoptees and immigrant families in Sweden. Clin Exp Allergy 2011;41:1108-1115.

25 Eldeirawi KM, Persky VW: Associations of physician-diagnosed asthma with country of residence in the first year of life and other immigration-related factors: Chicago Asthma School Study. Ann Allergy Asthma Immunol 2007;99:236-243.

26 Kuehni CE, Strippoli MP, Low N, Silverman M: Asthma in young South Asian women living in the United Kingdom: the importance of early life. Clin Exp Allergy 2007;37:47-53.

27 Hjern A, Rasmussen F, Hedlin G: Age at adoption, ethnicity and atopic disorder: a study of internationally adopted young men in Sweden. Pediatr Allergy Immunol 1999;10: 101-106.

28 Kalyoncu AF, Stålenheim G: Survey on the allergic status in a Turkish population in Sweden. Allergol Immunopathol (Madr) 1993;21: 11-14.

29 Kalyoncu AF, Stålenheim G: Serum IgE levels and allergic spectra in immigrants to Sweden. Allergy 1992;47:277-280.

30 Asseyr AF, Businco L: Atopic sensitization in children of Somali immigrants in Italy. J Investig Allergol Clin Immunol 1994;4:192-196.

31 Dervaderics M, Fust G, Otos M, Barok J, Pataky G: Differences in the sensitisation to ragweed pollen and occurrence of late summer allergic symptoms between native and immigrant workers of the nuclear power plant of Hungary. Immunol Invest 2002;31:29-40.
32 Goren AI, Bruderman I: Pulmonary functions and respiratory symptoms and diseases among adult Israelis: variations by country of origin. Isr J Med Sci 1986;22:761-765.

33 von Mutius E, Weiland SK, Fritzsch C, Duhme $\mathrm{H}, \mathrm{Keil} \mathrm{U}$ : Increasing prevalence of hay fever and atopy among children in Leipzig, East Germany. Lancet 1998;351:862866.

34 von Mutius E: Allergies, infections and the hygiene hypothesis - the epidemiological evidence. Immunobiology 2007;212:433-439.

35 Scrivener S, Yemaneberhan H, Zebenigus M, Tilahun D, Girma S, Ali S, McElroy P, Custovic A, Woodcock A, Pritchard D, Venn A, Britton J: Independent effects of intestinal parasite infection and domestic allergen exposure on risk of wheeze in Ethiopia: a nested case-control study. Lancet 2001;358:14931499.

36 Arruda LK, Santos AB: Immunologic responses to common antigens in helminthic infections and allergic disease. Curr Opin Allergy Clin Immunol 2005;5:399-402.

37 Fishbein AB, Fuleihan RL: The hygiene hypothesis revisited: does exposure to infectious agents protect us from allergy? Curr Opin Pediatr 2012;24:98-102.

38 Daley D: The evolution of the hygiene hypothesis: the role of early-life exposures to viruses and microbes and their relationship to asthma and allergic diseases. Curr Opin Allergy Clin Immunol 2014;14:390-396.

39 Wills-Karp M, Santeliz J, Karp CL: The germless theory of allergic disease: revisiting the hygiene hypothesis. Nat Rev Immunol 2001; 1:69-75.

40 Cardoso LS, Oliveira SC, Góes AM, Oliveira RR, Pacífico LG, Marinho FV, Fonseca CT, Cardoso FC, Carvalho EM, Araujo MI: Schistosoma mansoni antigens modulate the allergic response in a murine model of ovalbumininduced airway inflammation. Clin Exp Immunol 2010;160:266-274.

41 Tang L, Chen Y, Wang L, Zhang S, Zeng X, Yi $\mathrm{X}$ : Identification and characterization of peptides mimicking the epitopes of metalloprotease of Schistosoma japonicum. Cell Mol Immunol 2005;2:219-223.

42 Santiago HC, LeeVan E, Bennuru S, RibeiroGomes F, Mueller E, Wilson M, Wynn T, Garboczi D, Urban J, Mitre E, Nutman TB: Molecular mimicry between cockroach and helminth glutathione S-transferases promotes cross-reactivity and cross-sensitization. J Allergy Clin Immunol 2012;130:248256.e9.

43 Santos $A B$, Rocha GM, Oliver C, Ferriani VP, Lima RC, Palma MS, Sales V, Aalberse RC, Chapman MD, Arruda LK: Crossreactive IgE antibody responses to tropomyosins from Ascaris lumbricoides and cockroach. J Allergy Clin Immunol 2008;121: 1040-1046.e1. 
44 Santiago HC, Bennuru S, Boyd A, Eberhard M, Nutman TB: Structural and immunologic cross-reactivity among filarial and mite tropomyosin: implications for the hygiene hypothesis. J Allergy Clin Immunol 2011;127: 479-486.

45 Santiago HC, Bennuru S, Ribeiro JM, Nutman TB: Structural differences between human proteins and aero- and microbial allergens define allergenicity. PLoS One 2012; 7:e40552.

46 Yazdanbakhsh M, van den Biggelaar A, Maizels RM: Th2 responses without atopy: immunoregulation in chronic helminth infections and reduced allergic disease. Trends Immunol 2001;22:372-377.

47 Bielory BP, Mainardi T, Rottem M: Evolutionary immune response to conserved domains in parasites and aeroallergens. Allergy Asthma Proc 2013;34:93-102.
48 Hartmann S, Schnoeller C, Dahten A, Avagyan A, Rausch S, Lendner M, Bocian C, Pillai S, Loddenkemper C, Lucius R, Worm M, Hamelmann E: Gastrointestinal nematode infection interferes with experimental allergic airway inflammation but not atopic dermatitis. Clin Exp Allergy 2009;39:1585-1596.

49 Daniłowicz-Luebert E, Steinfelder S, Kühl AA, Drozdenko G, Lucius R, Worm M, Hamelmann E, Hartmann S: A nematode immunomodulator suppresses grass pollen-specific allergic responses by controlling excessive Th2 inflammation. Int J Parasitol 2013; 43:201-210.

50 Fallon PG, Mangan NE: Suppression of TH2type allergic reactions by helminth infection. Nat Rev Immunol 2007;7:220-230.
51 Brown EM, Arrieta MC, Finlay BB: A fresh look at the hygiene hypothesis: how intestinal microbial exposure drives immune effector responses in atopic disease. Semin Immunol 2013;25:378-387.

52 Bager P, Arnved J, Rønborg S, Wohlfahrt J, Poulsen LK, Westergaard T, et al: Trichuris suis ova therapy for allergic rhinitis: a randomized, double-blind, placebo- controlled clinical trial. J Allergy Clin Immunol 2010; 125:123-130.

53 Summers RW, Elliot DE, Weinstock JV: Trichuris suis might be effective in treating allergic rhinitis. J Allergy Clin Immunol 2010; 125:766-767.

54 Hepworth MR, Hamelmann E, Lucius R, Hartmann S: Looking into the future of Trichuris suis therapy. J Allergy Clin Immunol 2010;125:767-768. 